DOI: 10.12957/demetra.2015.15933

\title{
Reflexões sobre o método etnográfico para apreensão das políticas sociais no campo da Alimentação e Nutrição: notas de pesquisa em uma cozinha comunitária
}

\section{Reflections on the ethnographic method for apprehension of social policies in the field of Food and Nutrition: research notes in a community kitchen}

Helisa Canfield de Castro

Maria Eunice Maciel'

\section{Universidade Federal do Rio Grande do Sul. Instituto de Filosofia e Ciências Humanas, Departamento de Antropologia, Programa de Pós-Graduação em Antropologia Social. Porto Alegre-RS, Brasil.}

Correspondência / Correspondence Helisa Canfield de Castro E-mail: helisa_nut@hotmail.com

\section{Resumo}

Esta comunicação propõe refletir sobre a pertinência do método etnográfico para a apreensão das políticas sociais no campo da Alimentação e Nutrição. Para tanto, parte-se de dados de uma pesquisa realizada em uma cozinha comunitária sediada em unidade de triagem e compostagem de resíduos (UTC) - popularmente conhecido como "lixão" - em um bairro da periferia de Porto Alegre-RS. Argumenta-se que o mérito desta pesquisa assenta-se no seu tradicional método, a etnografia, a qual envolve um conjunto de concepções e procedimentos que nos conduzirá ao ponto de vista dos grupos pesquisados através de um trabalho intensivo in loco. Procuraremos, primeiro, trazer algumas definições e caracterizações das políticas sociais que tratam da Segurança Alimentar e Nutricional, bem como do contexto etnográfico para em seguida, com base em algumas notas etnográficas, tentar elucidar, ainda que inicialmente, possíveis apropriações que os atores fazem sobre a cozinha comunitária e os demais programas ali executados. Sem pretensões de encerrar o debate, na parte final a arguição se dá em favor da pertinência do método para uma compreensão profunda dos sentidos dados a programas sociais e para a problematização das diferentes lógicas que habitam o contexto estudado, permitindo repensar criticamente as ações governamentais em torno do tema da SAN.

Palavras-chave: Alimentação. Políticas Públicas. Etnografia. Classe Social. Segurança Alimentar e Nutricional. 


\section{Abstract}

This paper aims to reflect on the relevance of the ethnographic method to the seizure of social policies in the field of Food and Nutrition. It is based on data from a survey conducted in a community kitchen from a sorting and waste composting unit (UTC) - popularly known as "dump" - in a neighborhood on the outskirts of Porto Alegre-RS, Brazil. It is argued that the merit of this research is its traditional method, ethnography, which involves a set of concepts and procedures that will lead us to the point of view of the groups surveyed through an intensive work-site. Firstly we seek to bring some definitions and characterizations of social policies that address Food and Nutrition Security (FNS) as well as the ethnographic context; then, based on some ethnographic notes, we will try to elucidate, although initially, possible appropriations that actors do on the community kitchen and on other programs there. Without pretending to wind up the debate, at the end the discussion is in favor of the relevance of the method for a deep understanding of the directions given to social programs and to the questioning of the different logics that inhabit the context studied, allowing critically rethink the government's actions concerning FNS.

Key words: Food. Public Policies. Ethnography. Social Class. Food and Nutrition Security.

\section{Introdução}

Esta comunicação se propõe a refletir sobre a pertinência do método etnográfico para a apreensão das dinâmicas envolvidas na execução de programas sociais na área da Segurança Alimentar e Nutricional. Para tanto, parte-se de dados de pesquisa realizada nos meses de janeiro a outubro de 2014, em uma cozinha comunitária sediada em uma Unidade de Triagem e Compostagem de Resíduos (UTC) - popularmente conhecido como "lixão" - em um bairro periférico de Porto Alegre-RS.

As cozinhas comunitárias são um dos programas de Segurança Alimentar e Nutricional (SAN) e compõem as ações da Política Nacional de Segurança Alimentar e Nutricional (PNSAN), ainda em construção, mas cujo instrumento legal mais recente é a Lei Orgânica de Segurança Alimentar (LOSAN), a qual norteia ações e define os conceitos envolvidos no tema."

* Segundo a Lei Orgânica de Segurança Alimentar e Nutricional - LOSAN (Lei no 11.346, de 15 de setembro de 2006), por Segurança Alimentar e Nutricional (SAN) entende-se a realização do direito de todos ao acesso regular e permanente a alimentos de qualidade, em quantidade suficiente, sem comprometer o acesso a outras necessidades essenciais. 
Tomando como base teórico-metodológica a ciência da Antropologia, argumenta-se que o mérito da mesma para a pesquisa em questão assenta-se no seu tradicional método, a etnografia, que envolve um conjunto de concepções e procedimentos que nos conduzirá ao ponto de vista dos grupos pesquisados através de um trabalho intensivo in loco.

Cabe ressaltar que a opção metodológica está indissociavelmente ligada às escolhas e posturas teóricas, relacionando-se intimamente com nosso objetivo de compreender as dinâmicas específicas de um dado contexto sociocultural e, desta maneira, entender as formas locais de apropriação de uma política pública - materializada no espaço social da cozinha e na comida oferecida - e sua dimensão simbólica para a população envolvida. Nessa perspectiva, tomando as práticas alimentares dos atores, indaga-se: qual o sentido das ações de governo para os atores que dela usufruem? E em que medida os programas sociais executados interferem na maneira desses atores se alimentarem?

Buscamos explorar aqui o método etnográfico enquanto uma forma eficiente para pensar as questões acima mencionadas, explorando interseções cabíveis entre as subáreas da Antropologia Política e da Antropologia da Alimentação. Nessas condições, como sugere Abélès, ${ }^{1}$ trata-se de apreender a dinâmica das estruturas, tanto quanto as relações que as constituem, considerando as incompatibilidades, contradições, tensões e o movimento inerente a todas as sociedades. Conjugando a comida com seus comedores, distribuidores e doadores, procuramos captar as dinâmicas que marcam a execução desse programa para entender não só como ele funciona efetivamente, mas qual o sentido para as pessoas às quais ele se destina.

No decorrer deste esforço textual, procuraremos trazer, primeiro, algumas definições e caracterizações em torno dos programas que envolvem o contexto etnográfico, bem como do espaço social em que se desenvolve a pesquisa. Em seguida, com base em algumas notas etnográficas, tentaremos elucidar, ainda que inicialmente, possíveis apropriações que os atores fazem sobre a cozinha comunitária e sobre os demais programas ali executados, para ao final argumentar em favor da pertinência do enfoque etnográfico para compreender a problemática aqui exposta.

\section{Conectando políticas, instâncias e atores}

Segundo o Ministério do Desenvolvimento Social e Combate à Fome (MDS), ${ }^{2}$ órgão responsável pela execução de programas de Segurança Alimentar e Nutricional, o Programa de Cozinhas Comunitárias compõe uma rede de equipamentos públicos de alimentaçãoe nutrição cujas bases estão assentadas na noção de Direito Humano à Alimentação Adequada (DHAA).** Esses equipamentos são locais - dentre os quais se destacam os restaurantes populares e as cozinhas

** Para mais informações, ver http://www.mds.gov.br/segurancaalimentar/equipamentos/cozinhascomunitarias 
comunitárias - destinados ao preparo de refeições saudáveis, que devem ser distribuídas gratuitamente ou a preços acessíveis à população em situação de vulnerabilidade social.Com o intuito de atender às populações em situação de pobreza e extrema pobreza, as cozinhas são instaladas em regiões socialmente vulneráveis, com baixo índice de desenvolvimento humano (IDH), normalmente em bolsões de pobreza situados em periferias e regiões metropolitanas.

Conforme diretrizes do programa, o público-alvo das cozinhas comunitárias deve ser formado por pessoas em situação de insegurança alimentar e/ou vulnerabilidade social, preferencialmente aquelas indicadas pelos Centros de Referência em Assistência Social (CRAS). Cada unidade deve estar comprometida com a produção mínima de 100 refeições por dia, durante pelo menos cinco dias por semana. Atualmente, são 407 unidades que funcionam em 22 estados brasileiros, servindo cerca de 90 mil refeições diárias. ****

As cozinhas comunitárias ainda fazem parte da estrutura operacional do Sistema Nacional de Segurança Alimentar (SISAN), que articula entidades e instâncias que trabalham sob a bandeira da SAN - dentre os quais, ministérios, ONGs, universidades e conselhos federais, estaduais e municipais de SAN. Em consonância com a meta de erradicação da extrema pobreza proposta pelo atual governo, o SISAN busca potencializar a interlocução com outras políticas sociais relevantes para o alcance dessa população mais vulnerável, como o Programa Bancos de Alimentos, o Programa de Aquisição de Alimentos (PAA), além do incentivo a ações de geração de trabalho e renda nas próprias cozinhas e refeitórios.

Embora criado no âmbito do Governo Federal - particularmente, entre os ministérios de Desenvolvimento Social e Combate à Fome (MDS) e o Ministério de Desenvolvimento Agrário (MDA) -, o Programa de Cozinhas Comunitárias tem capilaridade em nível local, na medida em que suas atividades são executadas em espaços sociais específicos, geralmente em comunidades bem demarcadas, como é o caso da cozinha que embasa esta pesquisa.

Dessa dinâmica predominantemente local depreende-se a criação de convênios públicos entre as três esferas de governo - União, estados e prefeituras -, segundo os quais cabem à União o repasse dos recursos financeiros e o pagamento das estruturas para cozinhas e refeitórios (fogão, geladeira, coifa, mesas, bancos etc.). Após a implantação das unidades, os governos locais, municipais e estaduais devem estruturar equipe técnica específica para planejar e acompanhar as ações desenvolvidas no equipamento, além de assumirem a responsabilidade pela gestão e manutenção dos serviços, podendo, para tanto, firmar parcerias com organizações comunitárias e entidades sociais ligadas a programas de geração de trabalho e renda.

\footnotetext{
*** Dados constantes no Relatório de Informações Sociais do Ministério do Desenvolvimento Social, disponível em: http://aplicacoes.mds.gov.br/sagi/RIv3/geral/relatorio.php
} 
A cidade de Porto Alegre possui 18 unidades de cozinhas comunitárias, em sua maioria gerenciadas por entidades religiosas e que têm apoio e supervisão da prefeitura municipal, através da Coordenadoria de Segurança Alimentar e Nutricional Sustentável (COSANS). Conforme o programa, a prefeitura deve distribuir às unidades gêneros alimentícios que contribuam para a elaboração das refeições oferecidas. Assim o faz por meio de programas de distribuição de alimentos, como o Programa Fome Zero e o Programa de Aquisição de Alimentos. Embora o Estado assista com doações de certos itens, o abastecimento também deve ser garantido pelas entidades gestoras das unidades.

\section{Sobre o cenário da pesquisa}

O esforço etnográfico que aqui propomos se dá numa cozinha comunitária de uma UTC conhecida popularmente como "lixão" - no bairro Lomba do Pinheiro, na cidade de Porto AlegreRS, situado na região leste, na divisa com o município de Viamão. Atualmente, a Lomba do Pinheiro é uma região densamente povoada e marcada por intenso processo de ocupação irregular, abrigando vilas que carecem de infraestrutura e saneamento básico. No ano de 2000, a prefeitura municipal, através de seu Departamento Municipal de Limpeza Urbana (DMLU), instalou em um terreno de dez hectares a estação de transbordo de lixo do município. Lá é dado destino adequado ao lixo recolhido da cidade, conforme plano diretor de resíduos do município. Além da estrutura própria da prefeitura, o local abriga um galpão onde funciona, desde 2001, uma UTC.

Na unidade de reciclagem trabalham cerca de 100 recicladores que se organizaram - desde a concessão do galpão - em torno de uma associação formalizada: a Associação de Triagem de Resíduos Sólidos Domiciliares Lomba do Pinheiro. A jornada de trabalho tem início às 6 horas da manhã e é finalizada por volta das 16 horas. A atividade diária de trabalho gira em torno da seleção, em duas esteiras, dos resíduos domiciliares, orgânicos e secos, que são coletados na cidade. $\mathrm{Na}$ hipótese de localizarem material reciclável, o produto é destinado à comercialização pelos próprios trabalhadores da UTC. O restante é empregado na produção de composto orgânico (adubo), que também é vendido no próprio local. Nos galpões o material reciclável é categorizado conforme parâmetros preestabelecidos e que regem a Política Nacional sobre Resíduos Sólidos (PNRS): vidros, papéis, plásticos, ferro, PETs, papelão etc. Os materiais possuem uma hierarquia quanto ao valor de venda e são comercializados nos galpões para empresas que os utilizam como matéria-prima.

A maioria dos trabalhadores são mulheres. Embora haja jovens, a maior parte tem mais de 40 anos e começou a trabalhar com reciclagem após se aposentar. Os homens são na maioria jovens e filhos de associadas, à exceção de alguns homens mais velhos que seguiram o mesmo percurso das mulheres: inscreveram-se para trabalhar na associação depois de aposentados. São muitos 
os boatos sobre problemas com o uso de drogas, sobretudo o crack. Nessa medida é que as mães acabam por inscrever seus filhos para trabalharem na UTC, ficando assim sob cuidado permanente. Também há muitos relatos de casos de abuso de bebida alcóolica, sobretudo entre os mais velhos.

Embora haja algumas pessoas que migraram do meio rural, grande parte mora na cidade há muito tempo, nas vilas adjacentes a UTC. A maioria das pessoas é analfabeta. Dentre os jovens, são poucos os que finalizaram o segundo grau. Saber ler e escrever é uma distinção no que diz respeito à possibilidade de fazer parte da coordenação, embora não seja um pré-requisito para participar das negociações comerciais, afinal muitos não conhecem as letras mas sabem calcular. De par da intimidade social, percebe-se que são muitos os aparentados que trabalham na UTC. Entre os trabalhadores, é possível identificar pais e filhos, casais, irmãos, primos e famílias inteiras, como foram com o decorrer do tempo agregando-se à associação.

Cada um dos 94 recicladores recebe um valor mensal médio de 750 reais. O valor da remuneração irá depender do que efetivamente é vendido e este, por sua vez, depende do quanto é triado na unidade. Nessa lógica, quanto mais se recicla, mais oportunidade de venda há. De qualquer forma, o valor total é dividido igualmente entre todos os associados, sem distinção da função que exercem - nas esteiras triando os materiais, na fiscalização, na coordenação, na venda ou na cozinha.

Nessa estrutura, além dos galpões que abrigam as atividades de reciclagem, foi instalada em 2004 uma cozinha comunitária que - diferentemente da maioria das cozinhas de Porto Alegre, que são gerenciadas por entidades religiosas - é gerenciada pelos próprios trabalhadores da unidade, que ali diariamente almoçam e tomam café da manhã.

Trabalham na cozinha três associadas, que são designadas em assembleia geral. Duas delas Dona Helena e a filha Martha - são responsáveis pelo preparo das refeições, enquanto Cláudia**** é quem diariamente lava a louça do café e do almoço. De acordo com o projeto inicial, o abastecimento da cozinha deve se dar através de outros programas sociais coordenados pela prefeitura, dentre os quais o Programa de Aquisição de Alimentos (PAA) - em que os alimentos são comprados de pequenos agricultores da região e doados para as cozinhas - e o Programa Fome Zero - que distribui cestas básicas às unidades para que estas repassem às famílias para consumo doméstico.

Na Antropologia, que tem no trabalho de campo o principal símbolo de suas atividades de pesquisa, o próprio objeto da pesquisa é negociado: tanto no plano da interação com os atores, como no plano da construção ou da definição do problema pesquisado pelo antropólogo. Conforme sugerem Comaroff \& Comaroff, ${ }^{3}$ pretendemos fazer com que a pesquisa partisse, antes de tudo, dos "efeitos situados de ver ou do ouvir", e não de uma meta-narrativa ou teoria totalizante sobre

**** Embora se tenha o consentimento por parte de nossas interlocutoras, os nomes aqui transcritos foram
trocados por uma questão ética. O mesmo se dará com os demais nomes próprios citados no decorrer do texto. 
o objeto em questão. Nesse sentido, os referenciais teóricos adotados serviram mais como caixas de ferramentas, conforme indica Foucault, ${ }^{4}$ os quais permitiram forjar instrumentos de análise sobre a realidade experienciada em campo, bem como sobre a prática de antropóloga. Isso significa que "se trata de construir não um sistema explicativo, mas um instrumento pertinente a uma lógica específica, capaz de captar as relações e as dinâmicas que se engajam em torno delas" (p. 251).

Assim, nossa entrada e aceitação em campo foram um processo lento e gradual, no qual se procurou estabelecer vínculos sólidos com os informantes, embora o foco estivesse na observação etnográfica, a qual pressupõe o registro subjetivo do diário de campo e os fatos "duros" da realidade. No decorrer da pesquisa, optou-se pela realização de entrevistas semiestruturadas com interlocutores-chave, de modo a nos cercarmos dos processos históricos e ambientes daquele cenário, incluindo a própria concessão da cozinha comunitária. As entrevistas foram guiadas por questões como (1) a criação da associação, (2) a "conquista da cozinha comunitária”, (3) as formas de comer e de preparar os alimentos que predominavam antes, (4) além das próprias histórias de vida de cada entrevistado.

\section{A mistura que dá gosto: primeira nota etnográfica}

Embora se tenha feito inicialmente extenso trabalho documental, levantando dados referentes às definições oficiais e instâncias normativas com relação aos programas, dado o enfoque etnográfico, passamos a ter contato com as pessoas diretamente envolvidas nas atividades da cozinha. Pudemos então, gradativamente, identificar os desencontros entre o que é posto em termos de uma proposta política e o que de fato acontece em sua execução diária.

Um ponto nos parece central para o entendimento das dinâmicas locais e dos sentidos acerca da instalação da cozinha e do refeitório: a irregularidade das remessas de alimentos para o preparo das refeições por parte do Estado. Embora a distribuição por meio de outros programas sociais que visem à SAN seja prevista como meio de abastecimento, o que se percebe são falhas na periodicidade e no conhecimento, por parte de quem trabalha na cozinha, do que será efetivamente recebido.

Por meses consecutivos, chegam à cozinha somente arroz e feijão, ou como tivemos a oportunidade de presenciar, alguns quilos de laranja ou aipim em grandes sacos de estopa. De maneira completamente inesperada, as cozinheiras tiveram que separar os itens em condições de uso - já que muitos estavam podres - e distribuir o restante. Nesse cenário, parece impor-se uma lógica imediatista em torno do que fazer para o almoço. Prepara-se o que se tem, à revelia do que poderá chegar a qualquer momento. 
Ademais, as pessoas tendem a idealizar os programas a partir de experiências do passado. Nessa lógica, quando "funcionavam" com periodicidade na entrega e eram distribuídos alimentos variados, como arroz, feijão, farinha de trigo, farinha de milho, óleo, assim como produtos in natura, num tempo não tão distante, porque agora não haveria de funcionar de forma igual? $\mathrm{O}$ parece transparecer nessas dinâmicas é um grande hiato entre a comida que se pensa - ou que se quer - e a comida que efetivamente chega como doação pública. Transcrevemos a seguir a resposta de uma das cozinheiras, ao ser questionada sobre quais os alimentos chegam à cozinha por meio da prefeitura:

[...] o PAA não está indo por burocracia, não andaram assinando uns papéis... daío agente nem espera mesmo porque comer é diário, é necessário... se formos esperar... O jeito é trazer nossa mistura e contar como o arroz e feijão do governo. De nada adianta vir só um monte de batata ou um monte de aipim e ainda por cima tudo de uma vez só e sem avisar. A gente fica aflita sem saber o que fazer. Também ninguém quer comer todo dia a mesma coisa: só feijão e arroz.

Assim, o que se observa atualmente é que por atraso nos convênios firmados entre prefeitura e pequenos agricultores, poucos alimentos têm sido repassados à cozinha comunitária, por parte do Estado. Diante das burocracias envolvidas, somente arroz, feijão e leite em pó são garantidos. Esporadicamente alguns vegetais, como aipim, laranja, batata, são entregues, ainda que na lógica da incerteza. Se bem que seguidamente algumas mulheres aparecem trazendo das esteiras garrafinhas contendo óleo usado jogadas no lixo, o óleo, o açúcar, o sal e o café, considerados itens de primeira necessidade, são comprados pela associação.

Muitos trabalhadores reconhecem as falhas, por parte do Estado, no que diz respeito à entrega de alimentos. Mas também se percebe um sentimento de gratidão com relação ao espaço físico concedido. O sentido e a relevância do programa parece estarem relacionados à estrutura física da cozinha, à possibilidade de se ter um local onde fazer as refeições, mais do que nos alimentos doados.

Essas inconstâncias frente à necessidade de comer têm levado à redefinição das dinâmicas sociais que marcam o momento da refeição e de seu preparo. Uma das estratégias foi trazer a "mistura", categoria nativa para designar o complemento ao arroz e feijão. Cada trabalhador traz os ingredientes que serão preparados pelas cozinheiras e servidos individualmente, a fim de incrementar o almoço. Os ingredientes são na maioria dos casos comprados nos pequenos mercados nos arredores da UTC antes de iniciar a jornada de trabalho ou algumas vezes, como observado no curto intervalo para o descanso ainda durante o turno da manhã.

Diariamente Martha - filha de dona Helena e também cozinheira - toma nota em um caderno do nome da pessoa e o que deve ser preparado. Para cada um é feita uma preparação diferente, 
mas que em todos os casos acompanhará o arroz e o feijão: ovo, chuleta, massa instantânea, empanados de frango, coxa de galinha etc. Poucas pessoas compram salada como incremento. As que o fazem são algumas mulheres mais velhas, que dizem estarem "cuidando da saúde". Como o refeitório é pequeno, os trabalhadores se dividem em dois grupos na hora do almoço, de acordo com as esteiras em que trabalham. Próximo da hora do almoço - as cozinheiras colocam os potes individuais contendo cada mistura devidamente etiquetada com nomes em um carro quente tipo bufê. Conforme os recicladores chegam ao refeitório, formam uma fila. As cozinheiras servem os pratos com o arroz e o feijão e em seguida cada um vai à busca e sua "mistura" acondicionada no carro quente.

Nessa dinâmica, em que somente o arroz e o feijão são preparados para o "coletivo", os utensílios de grandes proporções próprios de uma cozinha industrial acabam ociosos, sendo usadas frigideiras e pequenas panelas para a feitura das diferentes "misturas". São as próprias cozinheiras que trazem as panelas de casa e "doam” à cozinha ou quando as recicladoras recolhem das esteiras panelas postas fora, levam-nas para serem utilizadas na cozinha.

Em certas ocasiões - geralmente por volta do dia do recebimento do salário - alguns recicladores organizam-se em pequenos grupos para comer algo mais elaborado, como panquecas, pizza de sardinha, massa com molho branco. Nesse caso, cada um contribui com alguma quantia em dinheiro, uma pessoa compra os ingredientes no mercado da redondeza e a cozinheira prepara conforme o desejado.

A alimentação - natural à sobrevivência da espécie humana - é posta em relevo pela ação social, evidenciando-se o que vem a ser uma refeição característica para o almoço desses trabalhadores: tem que ter carne ou ao menos ovo, batata, aipim, salada. Algo "que dá sustância, mas que seja variado. [...] Pobre com dinheiro quer carne, quer fartura" - comenta uma das frequentadoras do local. Ainda que o Estado assista com arroz e feijão, com o básico em termos de uma estrutura alimentar, a agência aqui é mobilizada ao se trazer a comida individual, ao agregar algo mais ao arroz e ao feijão doados.

Essa dinâmica, ainda que aponte lacunas nos programas sociais executados, acaba por fazer emergir subjetividades - tratadas aqui nos termos sugeridos por Ortner. ${ }^{5}$ Por meio desse rearranjo de ingredientes, são apontados os desejos, as vontades e gostos de cada um, evidenciando satisfações ligadas a uma refeição completa que comumente são negligenciadas ou pouco compreendidas, em se tratando de pessoas colocadas às margens sociais e econômicas. Age-se sobre as brechas deixadas pela política pública; dão-se as costas para a burocracia e se enfrenta o problema da falta de entrega de alimentos. Em todo caso, o que está em jogo é a necessidade da satisfação da qual nos fala Garine, ${ }^{6}$ alcançada pela comida, algo aquém do fato de serem assistidos pelo Estado ou caracterizados enquanto "grupo social vulnerável". 
Entretanto, embora haja reclamações por parte das cozinheiras e do grupo que coordena a associação, a grande parte dos trabalhadores não parece se abalar com a falta da entrega pelo PAA, já que nesses casos podem escolher individualmente o que irão comer no almoço. Lembrando De Garine, ${ }^{6}$ as "misturas" aqui representam uma possibilidade de se exteriorizar, de exercer de certo modo sua posição social no microcontexto em questão. Além disso, numa aproximação a Bourdieu, ${ }^{7}$ trazer ou não trazer o complemento diário, compartilhá-lo com os demais é sinal de prestígio e distinção dentro do grupo.

A pessoalização da doação: segunda nota etnográfica

Passado determinado período em campo, começamos a realizar entrevistas em profundidade com algumas pessoas que frequentam o refeitório. Na tentativa de reconstruir a história da associação e o processo que culminou da conquista da cozinha comunitária, entrevistamos as cozinheiras atuais e alguns trabalhadores que participaram desses momentos no passado.

Foi a partir de simples indagações como "de onde vem a comida?" que começamos a captar a falta de conhecimento do arsenal de siglas que compõem o campo semântico dos programas de distribuição de alimentos, bem como dos próprios programas. Com exceção do Programa Bolsa Família, nenhum outro programa social foi citado pelas pessoas. Em suas explicações sobre a origem do arroz e do feijão, nos era sempre indicado que a prefeitura os enviara; no entanto, sempre era dado destaque para as pessoas que vinham entregar os alimentos e solicitar assinaturas após a checagem dos itens doados.

Em entrevista realizada com o mais antigo associado da UTC e que come diariamente na cozinha, ele nos esclareceu:

Dona Rejane - a mulher da caneta - é quem nos dava quilos carne de porco e até outras vezes peixe. Ela vinha com a kombi e deixava isso tudo aqui [...] era uma fartura, mas tem um tempo ela parou de vir!

Na ocasião do almoço na cozinha da UTC, escutamos o seguinte comentário em tom de ironia: A Dilma tá querendo arrumar as coisas... é chata a mulher, mas tá certo. Tem que ter NIS, tem que estar bem cadastrado no cadastro único (para ganhar a comida); Não é eu que estou dizendo, tá!? Isso vem lá de cima... a gente não poder fazer nada... Senão vamos ser banidos.

As falas aqui transcritas nos permitem repensar o Estado ou os programas que eles representam não como algo inerte ou supraestrutural, ${ }^{8}$ mas como algo impregnado no cotidiano, longe de grandes abstrações, sobretudo em se tratando de políticas ligadas à alimentação. Nesse sentido, 
ele assume um rosto, uma figura contra quem reivindicar ou a quem se dirigir, ou simplesmente para se pensar as ações sociais.

Outra estratégia para receber alimentos foi a busca por doações de mantimentos no banco de alimentos coordenado pela Federação das Indústrias do Rio Grande do Sul (FIERGS). Walquiria, que coordena a cozinha, nos conta que descobriu essa oportunidade em uma reunião comunitária no bairro, mas que nem todos conseguem, pois há de se ter carro e uma instituição "regularizada", que seja apta a receber os alimentos. Com a ajuda de um carro do DMLU, a associação, uma vez cadastrada no banco, consegue receber alimentos que são doados por empresas da iniciativa privada e que são estocados e distribuídos pelo banco. Organizada a busca junto com parceiros do próprio lixão, e alguns trabalhadores, entre eles Seu Joares, descarregam da kombi mantimentos variados para a cozinha -- entre eles, farinha de milho, leite em pó, suco de uva, arroz, feijão, óleo e açúcar.

Nesse caso, o reconhecimento se dá através de seu Antônio, antigo lixeiro do DMLU, mas que devido à idade foi afastado e hoje presta serviços administrativos. Ele é o responsável por trazer as doações do Banco de Alimentos da FIERGS, e na lógica de pessoalização das doações, tornou-se a figura central, por vezes benevolente que "doa" a comida. Ainda que haja uma enorme estrutura organizacional e logística, critérios e normas que fazem parte do funcionamento desta iniciativa empresarial, em última análise é Seu Antônio quem recebe o prestígio e a admiração quando chega com a kombi farta e abastece o refeitório.

Embora a cozinha de fato represente uma importante ação de Estado e uma ampla estrutura para o combate à fome, na lógica da comunidade estudada os programas sociais são reduzidos aos alimentos que chegam (ou não) e reconhecidos através das próprias pessoas que se vinculam mais diretamente com a entrega dos mesmos. Nesse cenário, com a falta de periodicidade da entrega de comida, parece imperar uma lógica traduzida na frase da coordenadora da cozinha: "se veio (a comida) ok, se não, nós nos viramos entre nós mesmo". Seu José acaba por nem se importar que dona "Rejane do PAA" não venha, "pode-se comer o que se quer, comer o que se gosta [...] daí a batata frita impera".

Se os gestores municipais, estaduais e federais são guiados por uma perspectiva burocráticonormativa na formulação e execução do programa***** o que não é nossa intenção problematizar aqui -, no dia a dia dos que atuam na cozinha comunitária o espaço acaba por se tornar uma extensão de suas casas, um local de sociabilidade. Isso nos permite repensar as próprias práticas observadas com relação ao preparo e consumo de alimentos. Nas formas de temperar a comida, servir os comensais, enxugar e guardar a louça, varrer o refeitório. Tais gestos não deixam

\footnotetext{
***** Por perspectiva burocrático-normativa, seguimos a noção de Mudanó, ${ }^{16}$ que indica ser uma perspectiva que conforma, em parte, os modos de fazer e também de se pensar as políticas públicas enquanto entidades objetivas, resultado de decisões racionais, adotadas por governos, quadros técnicos, instituições formais que organizam ações com base em conhecimento igualmente racional, voltadas para resultados precisos e imediatos.
} 
de estar de acordo com as normas técnicas e sanitárias mas, em um ambiente especificamente familiar, adquirem um tom bastante doméstico. Outras aproximações com as dimensões do que se poderia representar como um lar são ainda captadas em pequenas ações como a reunião para fofocas após o almoço, o local para onde se vai para tomar um remédio diário, onde se guarda algo valioso achado nas esteiras.

\section{Sobre a relevância da etnografia para o campo das políticas públicas de alimentação}

A atividade da pesquisa é marcada, durante toda sua realização, pelo quadro teórico que o pesquisador adota, por sua visão do mundo e compromisso social, assim como pelos limites do conhecimento próprios de seu tempo.

Os dados brevemente expostos buscam contribuir para a argumentação da relevância da etnografia, sobretudo no seu poder de detectar perspectivas divergentes e interpretações alternativas. Esse mérito somente é possível tomando a própria aproximação gerada no campo como um material rico para repensar a realidade social. Se a questão que se coloca é a da identificação das dinâmicas e interações subjacentes à ordem social, argumentamos o quanto a prática etnográfica nos é favorável, captando as dimensões subjetivas das ações relacionadas ao comer - geralmente deixadas em segundo plano em estudos quantitativos. Numa aproximação a Florence Weber, ${ }^{9}$ trata-se de compreender o que fazem as pessoas observadas, e igualmente de compreender o que elas creem fazer. Nas palavras da autora:

[...] essa exigência etnográfica (em restituir as categorias do pensamento nativo), ainda que vastamente resultado do interesse dos durkheimianos pela língua e pelas classificações, remonta ainda a uma a definição weberiana que se interessa ao mesmo tempo pelo que pensam os atores, pelo que eles fazem e pelo que eles são (p. 152). ${ }^{9}$

Ao seguir as orientações de Roberto Cardoso de Oliveira, ${ }^{10}$ quando salienta a importância do olhar disciplinado e atento para perceber as nuances e peculiaridades desta "outra maneira de ser e estar no mundo", o método etnográfico tem-nos permitido explorar nossa própria sensibilidade para apreender realidades diferentes das nossas; escolhas diferentes das nossas. É nessa complexa interação produzida no campo de pesquisa que estamos alcançando as respostas para nossa indagação primeira, qual seja: qual o sentido do Programa de Cozinhas Comunitárias para os atores?

Num esforço meta-analítico - conforme nos sugere Magnani ${ }^{11} \mathrm{em}$ seu trabalho com populações urbanas -, o esforço etnográfico deve ser pensado como uma prática contínua e ordenada, mas igualmente sob o aspecto experiencial, descontínuo, em que são confrontadas em campo diferentes 
racionalidades e sensações, que levam em conta o que ocorre e acontece com o pesquisado e com o pesquisador. Nesse sentido, o que nos possibilita captar como as pessoas pensam, agem e reagem às dinâmicas envolvidas na execução de uma política pública acaba por ser um olhar de perto e de dentro, do qual nos fala Magnani. ${ }^{12}$

Em um cenário onde são executadas políticas públicas em alimentação, a metodologia nos conduz para uma constante problematização sobre a lógica social e política que preside as definições e as ações tomadas pelo Estado, partindo do ponto de vista nativo. Empreende-se, assim, um esforço sistemático de reformulação e revisão de pressupostos dados como certo na vida social, à luz de intensa confrontação dialógica com as categorias do próprio campo.

Assim, a particularidade da etnografia reside em um olhar que parta do ponto de vista nativo, considerando, para tanto, as especificidades do contexto sociocultural em que é executada, sem menosprezar as dinâmicas mais amplas que cercam uma sociedade capitalista urbana marcada por desigualdades sociais e econômicas.

Tal perspectiva nos leva a considerar que uma análise baseada em valores dos grupos dominantes não daria conta das situações vividas pelos grupos marginalizados. Isto porque tal análise costumava reduzir o grupo estudado à miséria, às táticas de sobrevivência e a uma adaptação passiva ao modo de vida dominante, não percebendo as positividades e a criatividade dos grupos em questão. Aqui o fenômeno da alimentação - tão íntimo, mas que carrega consigo dimensões de sociabilidade e de comensalidade da qual nos fala Fischler ${ }^{13}$ - passa a ser encarado, conforme já sugerido por Fonseca, ${ }^{14}$ com o "cuidado em não perder completamente de vista possíveis diferenças nas matrizes simbólicas que ressaltam a especificidades dos grupos subalternos” (p. 15).

Ao propor uma análise que recai sobre políticas públicas que repercutem no cotidiano das pessoas - no caso, uma prática corriqueira como a alimentação -, não buscamos nos limitar à mera diferenciação entre o que está escrito e o que de fato ocorre; nem mesmo propor uma análise centrada no estudo do Estado, do governo e suas práticas..$^{15}$

O interesse está em perceber como as pessoas pensam e em que medida tais programas impactam suas vidas diárias, partindo do seu próprio ponto de vista e da interação pesquisador/pesquisado dada em campo. Como sugere Franzé Mudanó ${ }^{16}$ (p. 233), cabe perceber "a posição dos agentes sociais e suas ações com relação à política pública [...] nos microprocessos simbólicos e práticos”.

Outro ponto que merece ser destacado é que, dado o terreno eminentemente político - de constantes confrontos e tensões em torno da distribuição e doação de alimentos -, sobretudo em época de eleições, nos pareceu muito profícua a adoção da perspectiva de Florence Weber ${ }^{17}$ (p. 27), para quem o etnógrafo deve antes de tudo, "observar e escutar as pessoas, e não interrogá-las, para preservar suas iniciativas de classificação e o domínio sobre as palavras". 
Ainda no que diz respeito ao comportamento alimentar, parece-nos ser mais eficiente uma observação profunda do que o uso de questionários rígidos no que se refere a perguntas pragmáticas para respostas objetivamente forjadas. Entendemos que isso poderia gerar constrangimento e/ou omissão por parte dos interlocutores, já que em se tratando do que se come, as pessoas tendem a confundir o real com o ideal, ainda mais sob atuais influências da mídia e do discurso biomédico sobre o que venha ser uma alimentação saudável e adequada.

É preciso atentar para o quanto as políticas públicas agem e impactam a vida das pessoas, mobilizando-as para a ação e reação frente a suas contingências. Essas agências, sobretudo tomando o caso da doação e da distribuição de alimentos, manifestam-se no cotidiano, nos comportamentos alimentares: o que comer, o que preparar, o que servir e o que reivindicar.

\section{Considerações finais}

Longe de buscar uma conclusão para a problemática em questão, esperamos contribuir para um campo de conhecimento baseado na reflexão crítica sobre a estruturação e ampliação de políticas sociais que visam ao combate à fome. Enfocamos, sobretudo, a heterogeneidade cultural que envolve a alimentação e as tensões estabelecidas no cotidiano de sua execução, a partir de uma visão que problematize como a política e o Estado são experienciados pelos atores sociais.

Se por um lado procuramos demonstrar que os programas governamentais não são algo inerte ou abstrato, mas representados por pessoas concretas que diariamente fazem sua gestão, da mesma forma é através de pessoas que os programas são percebidos e apropriados pela população.

Nesse sentido, buscamos evidenciar, com este exercício etnográfico, o quanto a Antropologia pode vir a somar no campo das políticas públicas a partir de sua metodologia, que pode implicar uma avaliação qualitativa baseada não no que devem ser as políticas, mas no que efetivamente elas representam para os atores que experimentam sua execução no dia a dia.

\section{Referências}

1. Abélès M. La antropología política: nuevos objetivos, nuevos objetos. Revista Internacional de Ciencias Sociales [Internet] 1995; (153): Antropología - Temas y Perspectivas: I. más allá de las lindes tradicionales. Disponível em: http://www.unesco.org/issj/rics153/titlepage153.html

2. Brasil. Ministério do Desenvolvimento Social e Combate à Fome. Programa de Aquisição de Alimentos - PAA [Internet]. Disponível em: www.mds.gov.br/segurancaalimentar/aquisicao-e-comercializacaoda-agricultura-familiar 
3. Comaroff J, Comaroff J. Ethnography on an awkward scale: postcolonial anthropology and the violence of abstraction. Ethnography 2003; 4:147-179.

4. Foucault M. Estratégia poder-saber. $2^{\mathrm{a}}$ ed. Rio de Janeiro: Forense Universitária; 2006.

5. Ortner SB. Subjetividade e crítica cultural. Horiz. Antropol. 2007; 13(28):375-405.

6. Garine I. Alimentação, culturas e sociedades. Correio da Unesco 1987; 15(7):4-7.

7. Bourdieu P. Capital simbólico e classes sociais. Novos Estud. CEBRAP [Internet] 2013; 96:105-115.

8. Das V, Poole D. El estado y sus márgenes. Etnografías comparadas. Cuadernos de Antropología Social 2008; (27):19-52.

9. Weber F. Práticas econômicas e formas ordinárias de cálculo. Mana 2002; 8(2):151-182.

10. Oliveira RC. O trabalho do antropólogo. Brasília: Editora da Unesp; 1998. 220 p.

11. Magnani JGC. Etnografia como prática e experiência. Horiz. Antropol. 2009, 15(32):129-156.

12. Magnani JGC. De perto e de dentro: notas para uma etnografia urbana de perto e de dentro: notas para uma etnografia urbana. Rev. Bras. Ci. Soc. 2002; 17(49):11-29.

13. Fischler C, Masson E. Manger. Français, Européens et Américains face à l'alimentation. Paris: Odile Jacob; 2008. 330p.

14. Fonseca C. Classe e a recusa etnográfica. In: Brites J, Fonseca C, organizadores. Etnografias da participação. Santa Cruz do Sul: EDUNISC; 2006. p. 13-33.

15. Miranda APM. Antropologia, estado moderno e poder: perspectivas e desafios de um campo em construção. Avã: Revista de Antropología 2005; (7):1-27.

16. Franzé Mudanó A. Perspectivas antropológicas y etnográficas de las políticas públicas. Revista de Antropología Social 2013; 22:9-23.

17. Weber F. Trabalho fora do trabalho: uma etnografia das percepções. Rio de Janeiro: Garamond; 2009. 384 p. 
